\title{
Avaliação microbiológica de hortaliças minimamente processadas disponíveis no mercado e servidas em redes de fast-food e em unidades de alimentação e nutrição nas cidades de Limeira e Campinas, São Paulo, Brasil
}

\author{
Fabíola de Lima Pena ${ }^{1}$, Karina Hass Paulo ${ }^{2}$, Larissa Soragni ${ }^{3}$, Leonardo Tomazeli Duarte ${ }^{4}$ e \\ Adriane Elisabete Costa Antunes ${ }^{5}$
}

O presente estudo buscou determinar a presença de contaminantes microbiológicos em 64 amostras de hortaliças minimamente processadas (HMP) nas cidades de Limeira e Campinas - São Paulo, Brasil, e verificar a adequação destes produtos com os parâmetros descritos na legislação vigente. Foram realizadas contagens de aeróbios mesófilos totais, coliformes à $35^{\circ} \mathrm{C}$ e $45^{\circ} \mathrm{C}$, E.coli e determinação da presença de Salmonella. Dentre as amostras, 69,2\% foram obtidas diretamente do comércio das cidades de Campinas e Limeira e 30,8\% de restaurantes e redes de fast-food das mesmas cidades. As amostras apresentaram contagens médias de aeróbios mesófilos totais na faixa de 3,8 a $10,4 \log \mathrm{UFC}^{-1}$. Para coliformes à $35^{\circ} \mathrm{C}$ foram observadas variações de contagens médias nas faixas de $1,1 \mathrm{a}>5,0 \log \mathrm{NMP} \mathrm{g}^{-1} \mathrm{e}$ no caso dos coliformes à $45^{\circ} \mathrm{C}$, desde valores abaixo do nível de detecção do método até 5,0 $\log \mathrm{NMP} \mathrm{g}{ }^{-1}$. Na análise de E.coli, foram encontrados valores de contagens médias desde abaixo do nível de detecção do método até $2,1 \log \mathrm{UFC}^{-1}$. Salmonella não foi observada em nenhuma das amostras analisadas. Aproximadamente 12\% do total de amostras encontravam-se fora dos padrões definidos na RDC no 12 de 2001. Outros parâmetros não definidos pela legislação brasileira apresentaram contagens insatisfatórias quando confrontadas às legislações de outros países. Melhorias no sistema produtivo são necessárias para garantir a qualidade das hortaliças e evitar a contaminação e possíveis danos à saúde dos consumidores.

Palavras-chave: microbiologia de alimentos, processamento mínimo, contaminação.

\footnotetext{
${ }^{1}$ Nutricionista, Faculdade de Ciências Aplicadas da Unicamp (FCA/UNICAMP).

2 Nutricionista, Faculdade de Ciências Aplicadas da Unicamp (FCA/UNICAMP).

${ }^{3}$ Nutricionista, Faculdade de Ciências Aplicadas da Unicamp (FCA/UNICAMP).

${ }^{4}$ Engenheiro Elétrico e Professor Doutor, Faculdade de Ciências Aplicadas da Unicamp (FCA/UNICAMP).

${ }^{5}$ Nutricionista e Professor Doutor, Faculdade de Ciências Aplicadas da Unicamp (FCA/UNICAMP). Correspondência: Faculdade de Ciências Aplicadas. Cidade Universitária de Limeira. Rua Pedro Zaccaria no 1.300, CEP: 13484-350, Jardim Santa Luiza, Limeira, SP. E-mail: adriane.antunes@fca.unicamp.br
} 


\section{Microbiological evaluation of minimally processed vegetables available on the market and served in fast-food chains and food services in the cities of Limeira and Campinas, São Paulo, Brazil}

The current study aimed to determine the presence of microbiological contaminants in 64 samples of minimally processed vegetables from the cities of Limeira and Campinas, São Paulo, Brazil, to verify the adequacy of these products according to the parameters described in current legislation. Total aerobic mesophilic counts, coliforms from $35^{\circ} \mathrm{C}$ to $45^{\circ} \mathrm{C}$, E. coli counts and determination of the presence of Salmonella were performed in this study. Of the samples, $69.2 \%$ were obtained from the supermarkets and $30.8 \%$ from restaurants and fast food chains. The vegetables presented mean counts of total aerobic mesophilic in the range from 3.8 to $10.4 \log \mathrm{CFU} \mathrm{g}^{-1}$. For coliforms at $35^{\circ} \mathrm{C}$ variations were observed in the mean counts from 1.1 to $>5.0 \log \mathrm{MPN} \mathrm{g}^{-1}$ and for coliforms at $45^{\circ} \mathrm{C}$, the variations were from values below the method detection level to $5.0 \log \mathrm{MPN} \mathrm{g}-1$. For the E.coli counts, the average scores were from values below the method detection level to $2.1 \log \mathrm{CFU} \mathrm{g}^{-1}$. Salmonella spp. was not found in any of the samples evaluated. About $12 \%$ of all samples did not conform with the standards set by the RDC no 12, 2001. Other parameters not defined by the Brazilian legislation presented unsatisfactory values when confronted to the laws of other countries. Improvements in the production system are necessary to ensure the quality of vegetables and avoid contamination and possible damage to the consumer's health.

Key-words: food microbiology, minimal processing, contamination.

\section{INTRODUÇÃO}

O consumo insuficiente de frutas e hortaliças é reconhecido com um dos principais fatores que contribuem para aumento da incidência de doenças crônicas não transmissíveis, responsáveis por 2,7 milhões de mortes anuais no mundo [1]. A Organização Mundial da Saúde (World Health Organization WHO) recomenda o consumo diário de $400 \mathrm{~g}$ de hortaliças e frutas, o que equivale a 5 porções por dia [2].

Em 2009, o Ministério da Saúde descreve que pesquisas anteriores indicavam que o consumo destes grupos de alimentos no Brasil era muito abaixo do indicado pela Organização Mundial da Saúde, sendo de aproximadamente $132 \mathrm{~g}$ diárias [3]. Em resposta a estes dados, tem sido observado um aumento no consumo de frutas e hortaliças, decorrente de mudanças nos hábitos dietéticos da população - devido à preocupação com a saúde - e também devido a melhorias no sistema produtivo e de processamento, distribuição e acesso a estes alimentos. O estudo Vigitel Brasil mostrou diminuição da variação de adultos que consomem cinco ou mais porções diárias de frutas entre as pesquisas de 2010 e 2011, subindo de um mínimo de 9,2\% para $11,3 \%$ dos indivíduos entrevistados [4, 5]. A Pesquisa de Orçamentos Familiares 2008-2009 apontou um aumento de $17,9 \%$ na aquisição domiciliar per capita média anual de frutas se comparada com a média apontada no mesmo estudo no ano de 2002-2003 [ 6 .

Dentre estes produtos, o segmento mais promissor é o de minimamente processados (MP) [7]. A praticidade das hortaliças MP, aliada à redução do lixo doméstico (já que apenas as partes comestíveis são adquiridas) são alguns dos fatores que alavancam a comercialização destes produtos.

O consumo de hortaliças frescas prépreparadas ou prontas para o consumo tornou-se popular devido ao fato de se encontrarem já higienizados e embalados [8]. Embora o custo das preparações com HMP seja mais elevado, existe uma compensação econômica pela menor demanda de tempo e mão-de-obra para lavagem e sanitização de folhosos, frutas e legumes, em geral fazendo com que alguns estabelecimentos alimentícios optem por sua aquisição [9]. Neste cenário pode-se destacar também que a forte inserção da mulher no mercado de trabalho, com a consequente redução do tempo disponível para preparo das refeições, também contribui para o crescimento do mercado de HMP ${ }^{[10]}$. 
O termo "minimamente processado" faz referência a um mínimo de operações de processamento que o produto deve sofrer com fins de desenvolver um alimento prático, atraente e seguro [11]. As etapas de processamento compreendem corte, higienização, classificação, sanitização, centrifugação, embalagem e estocagem. Alguns pontos são fundamentais para a execução destas etapas e obtenção de bons produtos, dentre os quais pode-se citar a qualidade da matéria prima e da água para limpeza, a aplicação de boas práticas de higiene no processo, a correta embalagem e a baixa temperatura de armazenamento [12].

No Brasil, as HMP estão comercialmente disponíveis há mais de vinte anos [13], com aumento significativo nos últimos anos [7. A modalidade de comercialização das hortaliças prontas para consumo é importante devido à combinação de fatores tais como conveniência, saúde, segurança e características sensoriais agradáveis ${ }^{[12,13,14]}$. A vida útil destes produtos necessita ser suficientemente longa para permitir a sua distribuição e comercialização regional [15], entretanto, o processamento mínimo pode ser responsável por um período de conservação menor deste alimento se comparado às mesmas não processadas.

Além dos benefícios descritos, o aumento no consumo de HMP trouxe também uma preocupação por parte das autoridades sanitárias relacionadas à qualidade higiênica destes produtos, uma vez que estão sendo consumidos em grande escala. As hortaliças não processadas não consistem num grande risco sanitário, visto ser de conhecimento comum a necessidade de higienização prévia ao consumo. Em contrapartida, as HMP são oferecidas ao consumidor prontas para o consumo, sem necessidade de lavagem, conforme rótulo de algumas marcas comerciais. Assim sendo, sua segurança microbiológica deve ser monitorada periodicamente.

No Brasil, no período de 2000 a 2013 foram registrados 9.510 surtos alimentares, sendo 118 destes relacionados ao consumo de hortaliças ${ }^{[16]}$. Não pode ser negligenciado o fato de que as HMP possam representar um risco maior do ponto de vista de higiene e segurança dos alimentos tendo em vista que não são consumidos no seu local de preparo, nem logo após seu processamento, como ocorre com as hortaliças in natura.
As HMP são susceptíveis à invasão microbiana devido à presença de rupturas em suas superfícies que podem resultar em aumento de contagens microbianas e estímulo aos mecanismos da fisiologia do próprio vegetal limitando sua vida útil [14]. As etapas de processamento propiciam a ação enzimática nestes produtos decorrentes do rompimento das células do vegetal, levando a injúrias no tecido e, na presença de oxigênio, estas enzimas desenvolvem coloração escura no produto [12, 8]. Ainda, a microbiota natural das hortaliças pode albergar microrganismos produtores de enzimas pectinolíticas as quais podem degradar a estrutura celular vegetal e desta forma disponibilizar mais nutrientes para atividade microbiana favorecendo multiplicação celular mais rápida [14]. Não deve ser negligenciada a quebra da cadeia do frio desde o processamento até o consumo, como um fator que favorece elevação da carga microbiana destas. Soma-se o fato de não haver controle adequado da temperatura de refrigeração nas gôndolas dos mercados.

Embora existam HMP destinadas para preparações que passam por processo de cocção (tais como mistura de hortaliças para sopas, yakissoba, etc.) alguns folhosos são de consumo in natura não ocorrendo uma etapa adicional para eliminação de possíveis patógenos alimentares. Esse fato aumenta a necessidade de garantia higiênico-sanitária destes produtos.

Considerando o exposto, este trabalho buscou analisar diversas amostras de hortaliças folhosas minimamente processadas, coletadas em duas situações: 1) obtidas do comércio; 2) coletadas em restaurantes e redes de fast-food, a fim de determinar a presença de contaminantes microbiológicos e verificar a adequação destes produtos com os parâmetros descritos na legislação vigente. Ambos os estabelecimentos, comércios e restaurantes, encontravam-se em uma das duas cidades determinadas pela equipe de estudo, a saber, Campinas e Limeira, São Paulo, Brasil.

O presente trabalho traz como contribuição a análise microbiológica de hortaliças minimamente processadas adquiridas no comércio (para simular a condição caseira de consumo) e consumidas em restaurantes e redes de fast-food. Desta forma é apresentado um panorama atual da segurança desses alimentos que são considerados prontos para o consumo não passando geralmente por novas etapas de sanitização imediatamente antes do consumo. 


\section{MATERIAL E MÉTODOS}

\section{Coleta das amostras}

Amostras comerciais de diferentes marcas foram adquiridas em mercados das cidades de Limeira e Campinas/SP, embaladas com material plástico transparente, sem modificação de atmosfera e com a mesma recomendação de temperatura de armazenamento, sendo aleatoriamente selecionadas 5 embalagens do mesmo lote por vegetal folhoso, sendo elas: alface americana (Lactuca sativa, variedade Delícia), alface crespa (Lactuca sativa variedade Grand Rapids), alface lisa (Lactuca sativa, variedade Babá), agrião (Nasturtium officinale), couve (Brassica oleracea), chicória (Cichorium endivia), rúcula (Eruca sativa), hourenso (Spinacia oleracea) e radicchio (Cichorium intybus), totalizando 9 produtos.

As amostras foram analisadas no mesmo dia da aquisição. As adquiridas na cidade de Campinas foram transportadas para Limeira em bolsas térmicas higienizadas contendo gelo reutilizável. $\mathrm{Na}$ impossibilidade de executar a análise no dia da compra, foram analisadas dentro do período de validade indicado nos rótulos dos produtos. As embalagens originais foram externamente sanitizadas com álcool $70 \%$ antes de serem abertas para coleta das amostras sendo empregada tesoura flambada em chama para abertura das embalagens.

Em restaurantes e redes de fast-food foram coletadas 19 amostras obtidas diretamente do local de consumo, utilizados os próprios utensílios do local para reproduzir as condições em que as hortaliças são servidas para/pelos comensais. Os vegetais coletados foram: alface americana (Lactuca sativa, variedade Delícia), alface crespa (Lactuca sativa variedade Grand Rapids), alface lisa (Lactuca sativa, variedade Babá), mix de alfaces crespa e americana, escarola (Cichorium endivia), rúcula (Eruca sativa), repolho (Brassica oleracea variedade Capitata) e salsa (Petroselinum crispum).

Amostras de aproximadamente 100 gramas coletadas foram armazenadas em sacos estéreis, identificados e encaminhados ao laboratório em bolsa térmica sanitizada com álcool $70 \%$ contendo gelo reutilizável. Para estas amostras, as análises foram realizadas no dia de coleta e contra-prova das mesmas armazenada a $-20^{\circ} \mathrm{C}$.

\section{Análises microbiológicas}

As análises realizadas foram contagem de aeróbios mesófilos totais, coliformes a $30-35^{\circ} \mathrm{C}$ e a $45^{\circ} \mathrm{C}$, E. coli e detecção de presença de Salmonella spp. nas amostras [17].

Para aeróbios mesófilos totais foi utilizado o meio de cultura Ágar Padrão de Contagem (PCA Difco/BD, EUA) e o corante Cloreto de Trifenil Tetrazólio (Triphenyltetrazol chloride - TTC - Merck, EUA) com incubação a $35 \pm 1^{\circ} \mathrm{C}$ por $48 \mathrm{~h}$.

Os coliformes a $30-35^{\circ} \mathrm{C}$ e $45^{\circ} \mathrm{C}$ foram determinados pelo método de Número Mais Provável (NMP) com a técnica de crescimento em tubos múltiplos em triplicata. Os meios de cultura utilizados foram Lauril Sulfato Triptose (LST - Oxoid, Inglaterra), Caldo Bile Verde Brilhante (Oxoid, Inglaterra), incubados a $35 \pm 1^{\circ} \mathrm{C}$ por $24 \mathrm{~h}-48 \mathrm{~h}$, e Caldo EC (Difco/BD, EUA) incubados a $45 \pm 1{ }^{\circ} \mathrm{C}$ por $24 \mathrm{~h}$. As amostras com positivação em Caldo EC foram inoculadas em Petrifilm EC (3M, Brasil) com incubação à $35 \pm 1^{\circ} \mathrm{C}$ for $24 \mathrm{~h}$.

A presença de Salmonella foi detectada de acordo com o método BAM/FDA (2007) conforme Silva et al. (2010) [17], com uso dos meios de cultura de pré-enriquecimento Caldo Lactosado (Difco/BD, EUA); de enriquecimento seletivo Caldo Tetrationato (TT - Oxoid, Inglaterra) e Caldo Selenito Cistina (SC Oxoid, Inglaterra). Estes foram incubados a $35^{\circ} \mathrm{C}$ por 24h. Na sequência, foi realizado o plaqueamento diferencial nos meios de cultura Ágar Hektoen Entérico (HE - Oxoid, Inglaterra), Ágar Salmonella Shigella (SS Oxoid, Inglaterra) e Ágar de Desoxicolato-LisinaXilose (XLD - Oxoid, Inglaterra). A incubação desta etapa foi à $35^{\circ} \mathrm{C}$ por $24 \mathrm{~h}$, com posterior avaliação da presença de reações típicas de Salmonella. Parte da massa de colônias típicas foi inoculada em tubos inclinados contendo Ágar Lisina Ferro (LIA - Difco, EUA) e Ágar Triplice Açúcar Ferro (TSI - Difco, EUA) com incubação a $35^{\circ} \mathrm{C}$ por $24 \mathrm{~h}$. Após a verificação de ocorrência de reações típicas de presença de Salmonella foram aplicados os testes sorológicos, utilizando o Sorokit para Salmonella (Probac, Brasil).

Os resultados das contagens foram comparados com Resolução da Diretoria Colegiada (RDC) no 12, de 2 de janeiro de 2001 [18] sendo as amostras comerciais consideradas representativas (pois número determinado de unidades amostrais estava de acordo com o plano de amostragem, ou seja $n=5$ ) e as 
obtidas dos restaurantes consideradas indicativas (porque $\mathrm{n}<5$ ).

As médias dos resultados das contagens de aeróbios mesófilos totais e $E$. coli foram expressos em $\log$ UFC. $^{-1}$, coliformes a 30 e $35^{\circ} \mathrm{C}$ em log NMP g-1 e Salmonella spp. como ausência ou presença.

\section{Análise estatística}

Os resultados obtidos nas análises microbiológicas de hortaliças adquiridas no comércio (primeiro grupo de amostras) foram comparados entre si com nível de significância de $5 \%$ e submetidos à análise de variância - ANOVA e ao teste de Tukey (Statystical Analysis System - SAS University Editon).

\section{RESULTADOS}

Um total de 64 amostras foi coletado das cidades de Limeira e Campinas - SP totalizando 13 tipos, quais sejam: alface americana, alface crespa, alface lisa, mix de alfaces crespa e americana, agrião, couve, chicória, escarola, repolho, rúcula, salsa, hourenso e radicchio.

Do total de amostras, 30,8\% (19 amostras) foram coletadas em unidades de alimentação, tais como restaurantes públicos e privados e redes de fast-food, amostras estas que foram adquiridas pelo estabelecimento já em sua forma processada. Em apenas um dos locais de coleta foi relatado aplicar-se uma sanitização adicional com solução de hipoclorito de sódio (concentração não informada), posterior à abertura da embalagem de HMP e antes de ser servido ao consumidor. O restante, $69,2 \%$ (45 amostras) foi coletado no comércio local, em sua embalagem fechada.

\section{Amostras adquiridas no comércio}

As amostras adquiridas no comércio que apresentaram os maiores níveis de contagem de aeróbios mesófilos totais foram alfaces crespa e americana, radicchio, rúcula e hourenso, as quais não diferiram estatisticamente entre si. Para estas amostras as contagens médias deste grupo de microrganismos indicadores ficou entre 6,6 e 7,7 log $\mathrm{UFC} \mathrm{g}^{-1}$ (Tabela 1). As amostras de couve apresentaram contagem média de 6,0 log UFC g-1, não diferindo estatisticamente das hortaliças supracitadas nem das amostras de agrião e chicória. A amostra com menor contagem de aeróbios mesófilos foi a alface lisa, possivelmente devido à morfologia destas folhas o que facilita sua lavagem e sanitização.

Tabela 1. Resultado da análise de aeróbios mesófilos totais em hortaliças minimamente processadas nas amostras indicativas e representativas, coletadas nas cidades de Limeira e Campinas (SP) no ano de 2014.

\begin{tabular}{|c|c|c|c|}
\hline \multicolumn{2}{|c|}{ Amostras comerciais } & \multicolumn{2}{|c|}{ Amostras coletadas em restaurantes } \\
\hline $\begin{array}{c}\text { Hortaliças } \\
\text { (no de amostras) }\end{array}$ & $\begin{array}{l}\text { Contagens } \\
\text { médias* }\end{array}$ & $\begin{array}{c}\text { Hortaliças } \\
\text { (no de amostras) }\end{array}$ & $\begin{array}{l}\text { Contagens } \\
\text { médias* }\end{array}$ \\
\hline Alface americana (5) & $6,98 \pm 0,52^{\mathrm{A}}$ & Alface americana (6) & $6,20 \pm 1,70$ \\
\hline Alface crespa (5) & $7,76 \pm 0,11 \mathrm{~A}$ & Alface crespa (4) & $6,45 \pm 1,14$ \\
\hline Alface lisa (5) & $3,86 \pm 0,40^{\mathrm{C}}$ & Alface lisa (1) & 6,80 \\
\hline Agrião (5) & $4,54 \pm 0,88^{\mathrm{B}, \mathrm{C}}$ & Mix de alfaces crespa e americana (1) & 6,10 \\
\hline Couve $(5)$ & $6,02 \pm 0,51 \mathrm{~A}, \mathrm{~B}$ & Escarola (2) & $6,60 \pm 0,28$ \\
\hline Chicória (5) & $4,30 \pm 1,23 \mathrm{~B}, \mathrm{C}$ & Repolho (2) & $5,80 \pm 0,99$ \\
\hline Rúcula (5) & $6,94 \pm 0,38^{A}$ & Rúcula (2) & $6,10 \pm 0,42$ \\
\hline Hourenso (5) & $6,62 \pm 0,25^{\mathrm{A}}$ & Salsa (1) & 10,40 \\
\hline Radicchio (5) & $6,98 \pm 1.84 \mathrm{~A}$ & & \\
\hline
\end{tabular}

${ }^{*} \log$ UFC $g^{-1} \pm$ desvio padrão

Contagens seguidas das mesmas letras não diferiram entre si a 5\% de significância.

Dentro do grupo dos coliformes as amostras de agrião apresentaram contagens médias de 3,7 e 3,3 $\log \mathrm{NMP} \mathrm{g}^{-1}$ de coliformes a $35^{\circ} \mathrm{C}$ e $45^{\circ} \mathrm{C}$, respectivamente (Tabela 2). Estas contagens não diferiram estatisticamente das amostras de hourenso e rúcula especificamente para coliformes a $35^{\circ} \mathrm{C}$, porém 
diferiram de todas as outras hortaliças para coliformes a $45^{\circ} \mathrm{C}$. Nas amostras de agrião analisadas foi confirmada a presença de E. coli. Destaca-se, no entanto, que foram analisadas 5 diferentes embalagens de um mesmo lote e destas apenas duas apresentaram a referida contaminação. O tamanho pequeno das folhas pode ter sido um fator que dificultou a higienização das mesmas e colaborou para uma maior contagem deste microrganismo. Nas amostras de couve também foi confirmada a presença de E. coli (3 entre 5 embalagens do mesmo lote). Nos demais vegetais analisados não foi confirmada presença deste potencial patógeno.

Tabela 2. Resultado das análises de coliformes à $35^{\circ} \mathrm{C}$, coliformes à $45^{\circ} \mathrm{C}$ e E. coli em hortaliças minimamente processadas nas amostras comerciais, coletadas nas cidades de Limeira e Campinas (SP) no ano de 2014.

\begin{tabular}{|c|c|c|c|}
\hline \multirow{2}{*}{$\begin{array}{l}\text { Amostras comerciais } \\
\text { (no de amostras) }\end{array}$} & \multicolumn{3}{|c|}{ Contagens médias } \\
\hline & Coliformes à $35^{\circ} C^{*}$ & Coliformes à $45^{\circ} C^{*}$ & E. coli** \\
\hline Alface americana (5) & $1,12 \pm 0,69^{\mathrm{C}}$ & $<0,50 \pm 0,00^{\mathrm{C}}$ & $<1,00 \pm 0,00^{B}$ \\
\hline Alface crespa (5) & $1,66 \pm 0,62 \mathrm{C}$ & $0,72 \pm 0,27 \mathrm{~B}, \mathrm{C}$ & $<1,00 \pm 0,00^{\mathrm{B}}$ \\
\hline Alface lisa (5) & $1,20 \pm 0,75^{\mathrm{C}}$ & $<0,50 \pm 0,00^{\mathrm{C}}$ & $<1,00 \pm 0,00^{\mathrm{B}}$ \\
\hline Agrião (5) & $3,70 \pm 0,72 \mathrm{A,B}$ & $3,32 \pm 1,45^{\mathrm{A}}$ & $2,16 \pm 1,59 \mathrm{~A}$ \\
\hline Couve (5) & $1,60 \pm 0,45^{\mathrm{C}}$ & $1,74 \pm 0,60^{\text {в }}$ & $1,24 \pm 0,30^{\mathrm{A}, \mathrm{B}}$ \\
\hline Chicória (5) & $1,86 \pm 0,65^{\mathrm{C}}$ & $<0,50 \pm 0,00^{\mathrm{C}}$ & $<1,00 \pm 0,00^{\text {в }}$ \\
\hline Rúcula (5) & $4,10 \pm 0,41^{\mathrm{A}}$ & $1,02 \pm 0,36^{\mathrm{B}, \mathrm{C}}$ & $<1,00 \pm 0,00^{\mathrm{B}}$ \\
\hline Hourenso (5) & $4,00 \pm 1,11^{\mathrm{A}}$ & $0,72 \pm 0,49 \mathrm{~B}, \mathrm{C}$ & $<1,00 \pm 0,00^{\mathrm{B}}$ \\
\hline Radicchio (5) & $2,20 \pm 1,05^{\mathrm{B}, \mathrm{C}}$ & $0,56 \pm 0,13 \mathrm{~B}, \mathrm{C}$ & $<1,00 \pm 0,00^{\mathrm{B}}$ \\
\hline
\end{tabular}

${ }^{*} \log$ NMP g $^{-1} \pm$ desvio padrão, ${ }^{* *} \log$ UFC $~^{-1} \pm$ desvio padrão

Contagens seguidas das mesmas letras não diferiram entre si a $5 \%$ de significância.

Em todas as amostras analisadas foi observada ausência de Salmonella spp. Para esta análise, a RDC no 12 (Brasil, 2001) [18] estabelece o plano de duas classes em que $n=5$ e c $=0$ e o critério é ausência em 25 gramas do produto, ou seja, a ocorrência de 1 unidade positiva para o patógeno entre as 5 analisadas leva à rejeição de todo o lote. Nestes casos é possível adotar uma mistura das alíquotas retiradas de cada unidade amostral, respeitando-se a proporção de uma parte em peso da amostra, para 10 partes em volume do meio de cultura em caldo. Com base nessa informação, para os folhosos adquiridos seria possível a análise de Salmonella spp. empregando-se uma única "amostra composta", ou seja, contendo alíquotas de cada uma das 5 embalagens adquiridas. No entanto, optou-se por fazer análise de cada uma das unidades amostrais, o que significa dizer que foi encontrada ausência de Salmonella spp. em $125 \mathrm{~g}$ de cada um dos lotes analisados de alface americana, alface lisa, alface crespa, couve, agrião, rúcula, chicória, radicchio e hourenso (amostras representativas).

\section{Amostras de restaurantes e redes de fast-food}

Para as amostras coletadas em restaurantes as contagens médias de aeróbios mesófilos totais ficaram na faixa de 5,8 até $6,8 \log \mathrm{UFC}^{-1}$ para as amostras de alface americana, crespa e lisa, mix de alfaces crespa e americana, escarola, rúcula e repolho. A única amostra com contagem expressivamente superior foi de salsa $(\mathrm{n}=1)$ com valor de 10,4 log UFC g-1 $\mathrm{g}^{-1}$ (Tabela 1$)$.

Para o grupo dos coliformes a salsa novamente destacou-se dentre as demais com contagem de $5 \mathrm{log}$ NMP g-1 tanto para coliformes a $35^{\circ} \mathrm{C}$ como para coliformes a $45^{\circ} \mathrm{C}$ (Tabela 3). No entanto, não foi confirmada a presença de E. coli para esta amostra, bem como para nenhuma das outras amostras coletadas em restaurantes $(\mathrm{n}=19)$. As amostras de alface americana $(\mathrm{n}=6)$, crespa $(\mathrm{n}=4)$ e lisa $(\mathrm{n}=1)$ apresentaram contagens entre 3,7 e $>5 \log \mathrm{NMP} \mathrm{g}^{-1}$ na contagem de coliformes a $35^{\circ} \mathrm{C}$ e, contrariamente ao observado nas amostras comercias analisadas, a alface lisa apresentou o maior valor. Dentre estas amostras, a alface crespa apresentou a maior contagem de coliformes a $45^{\circ} \mathrm{C}(1,3$ $\left.\log \mathrm{NMP}^{-1}\right)$.

Nenhuma das amostras de hortaliças folhosas minimamente processados obtidas dos restaurantes apresentou presença de Salmonella spp. 
Tabela 3. Resultado das análises de coliformes à $35^{\circ} \mathrm{C}$, coliformes à $45^{\circ} \mathrm{C}$ e E. coli em hortaliças minimamente processados nas amostras de restaurantes, coletadas nas cidades de Limeira e Campinas (SP) no ano de 2014.

\begin{tabular}{|c|c|c|c|}
\hline \multirow{2}{*}{$\begin{array}{c}\text { Amostras coletadas em restaurantes } \\
\text { (no de amostras) }\end{array}$} & \multicolumn{3}{|c|}{ Contagens médias } \\
\hline & Coliformes à $35^{\circ} \mathrm{C}^{*}$ & Coliformes à $45^{\circ} \mathrm{C}^{*}$ & E. coli** \\
\hline Alface americana $(6)$ & $3,73 \pm 1,57$ & $0,98 \pm 1,14$ & $<1,00 \pm 0,0$ \\
\hline Alface crespa (4) & $4,08 \pm 1,48$ & $1,38 \pm 0,96$ & $<1,00 \pm 0,0$ \\
\hline Alface lisa (1) & $>5,00 \pm 0,00$ & $<0,50 \pm 0,00$ & $<1,00 \pm 0,0$ \\
\hline Mix de alfaces crespa e americana (1) & $1,60 \pm 0,00$ & $1,10 \pm 0,00$ & $<1,00 \pm 0,0$ \\
\hline Escarola (2) & $>5,00 \pm 0,00$ & $<0,50 \pm 0,00$ & $<1,00 \pm 0,0$ \\
\hline Repolho (2) & $2,85 \pm 1,77$ & $0,90 \pm 0,57$ & $<1,00 \pm 0,0$ \\
\hline Rúcula (2) & $2,30 \pm 2,83$ & $0,53 \pm 0,04$ & $<1,00 \pm 0,0$ \\
\hline Salsa (1) & $>5,00 \pm 0,00$ & $5,00 \pm 0,00$ & $<1,00 \pm 0,0$ \\
\hline
\end{tabular}

${ }^{*} \log \mathrm{NMP} \mathrm{g}^{-1} \pm$ desvio padrão, ${ }^{* *} \log \mathrm{UFC} \mathrm{g}^{-1} \pm$ desvio padrão

\section{DISCUSSÃO}

O presente estudo observou que $12,5 \%(\mathrm{n}=8)$ do total de amostras (obtidas do comércio ou dos restaurantes e redes de fast food) estavam insatisfatórias segundo a RDC no 12 em todos os casos devido às contagens de coliformes à $45^{\circ} \mathrm{C}$ superiores ao limite determinado na legislação vigente. Assis e Uchida (2014) [19], obtiveram resultados nos quais 100\% das amostras de hortaliças minimamente processadas estavam próprias para o consumo. Diferentemente, Oliveira et al. (2011) [13] encontraram em seu estudo resultados que indicam que a maior parte dos folhosos analisados encontravam-se com baixa qualidade microbiológica.

A RDC no 12, que define critérios e padrões microbiológicos dos alimentos no Brasil, não determina padrões de contagens para bactérias aeróbias mesófilas totais, o que dificulta classificar a qualidade destes produtos por este indicador. A Health Public Agency, Inglaterra, determina como contagem satisfatória até $10^{6} \mathrm{UFC} / \mathrm{g}\left(6 \log \mathrm{UFC} \mathrm{g}^{-1}\right)$ para aeróbios mesofilos totais [20]. Adotando este parâmetro, $59 \%(\mathrm{n}=38)$ do total das amostras deste estudo encontram-se fora dos limites descritos como satisfatórios na legislação inglesa. Segundo Arruda et al. (2004) [21] alimentos que apresentam contagens de aeróbios mesófilos e coliformes a $35^{\circ} \mathrm{C}$ de $5-6 \log \mathrm{UFC} \mathrm{g}^{-1}$ devem ser considerados impróprios para o consumo humano, uma vez que nesta faixa de contagem há alterações sensoriais, risco de deterioração e consequente perda nutricional, além do favorecimento da multiplicação de patógenos.
A International Commission on Microbiological Specifications for Foods (ICMSF) indica que alimentos contendo contagens de microrganismos aeróbios mesófilos acima de 6 log UFC.g-1 podem apresentar sinais de decomposição com alterações no aroma, textura e aparência [1]. Ragaert et al. (2007) [14] observaram alterações sensoriais que resultaram em rejeição de HMP quando obtidas contagens microbianas acima de 7 a $8 \log$ UFC.g-1. No estudo de Campos et al. (2013) [22] 86\% das amostras de saladas MP analisadas foram consideradas como de qualidade microbiológica insatisfatória por apresentarem elevada contagem de aeróbios mesófilos totais adotando-se naquele estudo o limite de $6 \log$ UFC.g-1 ${ }^{-1}$.

Em geral a contagem total de microrganismos aeróbios mesófilos em HMP, após o processamento, varia entre 3.0 e $6.0 \mathrm{log}$ UFC $\mathrm{g}^{-1}$ [14]. As espécies microbianas predominantes durante a estocagem refrigerada geralmente abrangem Psendomonadeceae (em especial $P$. fluorescens) e Enterobacteriaceae (principalmente Erwinia herbicola e Rabnella aquatilis), além de bactérias lácticas (sobretudo Leuconostoc mesenteroides) [23, 24]. Apesar de vários trabalhos descreverem a relação de aeróbios mesófilos com a durabilidade do vegetal, é importante citar que o término da vida útil das HMP não está relacionado apenas à contagem total destes microrganismos, mas também ao tipo de microrganismo presente, em especial àqueles contendo enzimas pectinolíticas e outras, capazes de causar alterações sensoriais. 
Parte da microbiota natural das HMP é composta por microrganismos que não são patogênicos, apenas deteriorantes. Alguns fatores intrínsecos favorecem a degradação dos vegetais folhosos, tais como o alto teor de água, com atividade de água $>0,99{ }^{[14]}$ e o $\mathrm{pH}$ próximo à neutralidade. Estas propriedades favorecem o crescimento microbiano em especial quando nutrientes se tornam disponíveis, como no caso do processamento mínimo no qual ocorrem cortes e extravasamento de material intracelular $[14,7]$. Isso explica o porquê do período de conservação dos HMP ser geralmente menor do que das não processadas.

Nas amostras deste estudo foi encontrada a presença de bactérias da família Enterobacteriacea, correspondente aos coliformes totais (família composta pelas bactérias Klebisiella, Citrobacter, Enterobacter $e$ Escherichia) e que podem ser membros naturalmente presentes na microbiota dos vegetais folhosos.

Das legislações citadas, apenas a inglesa estabelece valores para contagens de coliformes a 30$35^{\circ} \mathrm{C}$ para estes produtos, classificando como de qualidade insatisfatória aqueles que apresentem contagens dos microrganismos da família Enterobacteriaceae acima de $10^{4}$ [20]. Neste cenário, 28\% $(\mathrm{n}=18)$ das amostras analisadas seriam consideradas impróprias.

É importante lembrar que este grupo de bactérias é indicador das condições de higiene e processamento das hortaliças, uma vez que podem ser facilmente inativados por produtos sanitizantes [17]. Seow et al. (2012) ${ }^{[25]}$ analisaram 13 saladas processadas, dentre outras hortaliças frescas vendidas em Singapura e encontraram uma faixa de contagem de 4,2 a 5,9 log UFC $\mathrm{g}^{-1}$ para coliformes à $35^{\circ} \mathrm{C}$, valores tão elevados quanto os obtidos no presente estudo.

A presença de Escherichia coli em cinco amostras comerciais $(7,8 \%$ do total de amostras) merece destaque. A E. coli é uma bactéria pertencente ao grupo de coliformes termotolerantes, ou também denominados coliformes à $45^{\circ} \mathrm{C}$ (um subgrupo dos coliformes totais), e representa um dos indicadores de possível contaminação de origem fecal. Tendo em vista a possibilidade de ser acompanhada da contaminação por outros patógenos de origem entérica é extremamente relevante encontrar baixas contagens deste microrganismo ${ }^{[1]}$. Apesar de ser habitante natural do trato intestinal dos animais e do homem, exercendo efeito benéfico na supressão de bactérias prejudiciais ao organismo e na síntese de vitaminas, existem cepas capazes de provocar doenças em humanos, tais como a E. coli $\mathrm{O} 157: \mathrm{H} 7$ e E. coli O104:H4. Estas cepas são classificadas como de perigo severo, com risco de morte e sequelas [26].

A RDC 12 não define valores limites para contagem de E. coli, entretanto, preconiza que, caso seja determinada a presença deste microrganismo, deve constar no laudo analítico [18]. Para os coliformes a $45^{\circ} \mathrm{C}$, o valor máximo de contagem permitido é de $10^{2}$ $\mathrm{NMP} \mathrm{g}^{-1}\left(2 \log \mathrm{NMP} \mathrm{g}^{-1}\right)$. Das amostras analisadas neste estudo, $12,5 \%(\mathrm{n}=8)$ apresentaram valores entre 2,3 e $5,0 \log \mathrm{NMP}^{-1}$.

O Decreto Real 3484/2000 da Espanha [27] estabelece para alimentos preparados e embalados a base de vegetais crus o limite de contagem de E.coli de $10^{2}$ UFC $\mathrm{g}^{-1}$. Tomando este limite, duas das cinco amostras positivas para E. coli apresentariam qualidade microbiológica insatisfatória, totalizando 3,1\% do total de amostras analisadas.

Em nenhuma das amostras analisadas foi detectada a presença de Salmonella spp. Resultado semelhante foi observado por Santos et al. (2012) [1] e Campos et al. (2013) [22]. Este microrganismo deve estar ausente em todas as amostras indicativas $\mathrm{e}$ representativas, segundo a RDC 12, de 2 de janeiro de 2001. Diferentemente, diversos patógenos, incluindo a Salmonella foram encontrados em saladas minimamente processadas no trabalho de Oliveira (2011) [13]. Foram analisadas 162 amostras comercializadas no Brasil nas quais detectou-se presença de E. coli em 53,1\% ( $\mathrm{n}=86$ ), Listeria spp. em 3,7\% ( $\mathrm{n}=6)$ e Salmonella em 1,2\% ( $\mathrm{n}=2)$ das amostras.

A ausência de Salmonella e E. coli nas amostras obtidas dos restaurantes e redes de fast-food das cidades de Limeira e Campinas apontam para um possível desenvolvimento adequado de Boas Práticas Agrícolas no cultivo destes produtos e/ou emprego de Boas Práticas de Fabricação nas plantas de processamento, bem como nas unidades produtoras de refeições e lanches.

Segundo a FAO/WHO (2008) [28] vegetais verdes folhosos são os produtos mais frequentemente implicados em surtos de Salmonella e Escherichia coli O157:H7. É importante salientar que não existem garantias de sucesso absoluto na erradicação de microrganismos patogênicos em alimentos précontaminados, utilizando a lavagem e o emprego de 
sanitizantes ${ }^{[8]}$, sendo necessário máximo cuidado nas técnicas de cultivo para minimizar o risco de sua ocorrência.

A sanitização tradicional utiliza em sua maioria, soluções de hipoclorito e de quaternário de amônio, potencialmente prejudiciais à saúde do consumidor, quando em excesso. Apesar destes produtos serem eficazes na sanitização de hortaliças, métodos de sanitização mais seguros estão sendo desenvolvidos e estudados. Um estudo de sanitização de alfaces com agua ionizada, por exemplo, apresentou reduções decimais de até 4,5 ciclos logarítmicos na população $E$. coli $\mathrm{O} 157: \mathrm{H} 7$, inoculada intencionalmente no vegetal, demonstrando o potencial do composto como alternativa aos atuais sanitizantes utilizados [29].

Dos HMP avaliados nesta pesquisa a salsa (obtida de um restaurante) representou o alimento de maior risco microbiológico. Ao contrário das demais hortaliças deste estudo, a salsa é considerada um tempero e possivelmente o seu consumo ocorre em quantidade baixa. Ainda assim, o consumo de $10 \mathrm{~g}$ corresponderia a uma carga microbiana de 11,4 log UFC de aeróbios mesófilos totais e de $6 \log$ NMP de coliformes a $45^{\circ} \mathrm{C}$. No trabalho de Sant'Ana et al. (2014) [30] foram estabelecidos valores de $25 \mathrm{~g}, 50 \mathrm{~g}$ e $75 \mathrm{~g}$ como porções mínima, média e máxima de consumo de hortaliças MP. Portanto, para as demais HMP avaliadas neste trabalho, as quantidades médias de consumo devem se situar na faixa de $25 \mathrm{a} 75 \mathrm{~g}$.

Mesmo não sendo detectada a presença dos patógenos E. coli e Salmonella na referida amostra de salsa, não se deve descartar a possibilidade da existência de outro patógeno e em quantidade compatível com sua dose infectante correspondente. $\mathrm{E}$ ainda, se a presença de patógenos fosse totalmente descartada, é importante considerar a possibilidade de a salsa contaminar preparações às quais pudesse ser adicionada, em especial pelo fato de que este tempero costuma ser acrescentado por último nas preparações, não cozido ou cozido por pouco tempo. Srebernich (2007) ${ }^{[15]}$ destaca que, entre as hortaliças minimamente processadas e comercializadas em Campinas/SP, o cheiro verde (salsa e cebolinha) apresenta os maiores níveis de contaminação microbiana, com elevadas contagens de coliformes totais (contagem máxima de 7,7 log UFC/g) e fungos (contagem máxima de 5,8 log $\mathrm{UFC} / \mathrm{g})$.
Algumas das contagens elevadas de microrganismos discutidos neste trabalho podem ser atribuídas a manipulação inadequada no processamento e falhas nos procedimentos de produção como, por exemplo, a sanitização incorreta dos equipamentos utilizados. Estas falhas podem levar a um incremento da carga microbiana e comprometer a qualidade e segurança destes produtos [8]. Ressalta-se que algumas bactérias são capazes de produzir biofilmes, o que representa um obstáculo adicional para sua remoção tanto de equipamentos como dos próprios vegetais folhosos e outros alimentos, o que enfatiza a necessidade de limpeza mecânica associada ao emprego de sanitizantes. A possibilidade de contaminação cruzada nas plantas de processamento das HMP também deve ser considerada, não apenas por contato com superfícies e utensílios sem higienização adequada ou por más práticas dos manipuladores, mas também por contaminação entre as próprias folhas do vegetal. Algumas destas (por exemplo folhas mais externas em uma cabeça de alface) podem apresentar carga microbiana mais elevada que o interior do alimento.

Além dos corretos procedimentos de higienização das hortaliças, equipamentos e superfícies, é recomendado nos setores de produção e alimentação um rodízio entre os agentes sanitizantes aplicados de modo a evitar o desenvolvimento de resistência pelos microrganismos ${ }^{[15]}$.

Nas Unidades de Alimentação e Nutrição (UANs) e lanchonetes que optam pelo emprego de HMP é recomendável escolher marcas de boa procedência.

\section{CONCLUSÕES}

O presente estudo analisou um total de 64 amostras, dentre as quais 12,5\% encontravam-se fora dos padrões definidos na RDC no 12 , de 2 de janeiro de 2001. É importante salientar, entretanto, que alguns parâmetros analisados, tais como aeróbios mesófilos totais, coliformes a $35^{\circ} \mathrm{C}$ e E. coli não são definidos nesta legislação sendo que algumas amostras apresentaram contagens insatisfatórias quando confrontadas às legislações de outros países. Considerando este cenário, o alcance dos minimamente processados na população, sua forma e frequência de consumo, melhorias no sistema produtivo são imprescindíveis e urgentes para se obter hortaliças de qualidade e evitar a contaminação e possíveis danos à saúde dos consumidores. 


\section{AGRADECIMENTOS}

Agradecemos ao Programa Institucional de Bolsas de Iniciação Científica (PIBIC/CNPq). Processo no 124658/2013-0, ao CNPq pela concessão de bolsas de Iniciação Científica e aos alunos das disciplinas NT505 e NT305 - Microbiologia dos Alimentos I e II, do 1o período letivo de 2014 da FCA/UNICAMP, pela coleta das amostras de UANs e lanchonetes.

\section{REFERÊNCIAS}

[1] Santos MI, Cavaco A, Gouveia J, Novais MR, Nogueira PJ, Pedroso 1, Ferreira MASS. Evaluation of minimally processed salads commercialized in Portugal. Food Control. 2012;23:275-281.

[2] Agudo A. Measuring intake of fruit and vegetables. In: Workshop on Fruit and Vegetables for Health, FAO/WHO. Kobe, Japão, 1-3 de Setembro; 2004.

[3] Brasil, Ministério da Saúde. Relatório Final - V Congresso Panamericano de incentivo ao consumo de frutas e hortaliças para a promoção da saúde. Brasília (DF): Ministério da Saúde; 2009.

[4] Ministério da Saúde, Secretaria de Vigilância em Saúde, Secretaria de Gestão Estratégica e Participativa. Vigitel Brasil 2010: vigilância de fatores de risco e proteção para doenças crônicas por inquérito telefônico. Brasília (DF): Ministério da Saúde; 2011.

[5] Ministério da Saúde, Secretaria de Vigilância em Saúde. Vigitel Brasil 2011: vigilância de fatores de risco e proteção para doenças crônicas por inquérito telefônico. Brasilia (DF): Ministério da Saúde; 2012.

[6] Ministério do Planejamento, Orçamento e Gestão, Instituto Brasileiro de Geografia e Estatística - IBGE. Pesquisa de Orçamentos Familiares 2008-2009: aquisição alimentar domiciliar per capita - Brasil e grandes regiões. Rio de Janeiro: Ministério do Planejamento, Orçamento e Gestão; 2010.

[7] Abadias M, Usuall J, Anguera M, Solsona C, Viñas I. Microbiologial quality of fresh, minimally-processed fruit and vegetables, and sprouts from retail establishments. Int J Food Microbiol. 2008;123:121-129.

[8] Maistro LC. Alface minimamente processada: uma revisão. Rev Nutr. 2001;14(3):219-224.

[9] Degiovanni GC, Japur CC, Sanches APLM, Mattos CHPS, Martins LS, Reis CV, et al. Hortaliças in natura ou minimamente processadas em unidades de alimentação e nutrição: quais aspectos devem ser considerados na sua aquisição? Rev Nutr. 2010;23(5):813-822.

[10] Secretaria de Agricultura e Desenvolvimento Rural (Emater - DF). Núcleo de Agronegócios. Pesquisa de mercado: hortaliças minimamente processadas em 2007. Agroinforme Emater-DF [internet]. 2008 [acesso em 15 jun 2014]. Disponível em: http://www.emater.df.gov.br

[11] Nantes JFD, Leonelli FCV. A estruturação da cadeia produtiva de vegetais minimamente processados. Rev. FAE. 2000;3(3):61-69.

[12] Ahvenainen R. New approaches in improving the shelf life of minimally processed fruit and vegetables. Trends Food Sci Tech. 1996;7:179-187.

[13] Oliveira MA, Souza VM, Bergamini AMM, Martinis ECP. Microbiological quality of ready-to-eat minimally processed vegetables consumed in Brazil. Food Control. 2011;2:1400-1403.

[14] Ragaert P, Devlieghere F, Debevere J. Role of microbiological and physiological spoilage mechanisms during storage of minimally processed vegetables. Postharvest Biol Tech. 2007;44:185-194.

[15] Srebernich SM. Utilização de dióxido de cloro e do ácido peracético como substitutos do hipoclorito de sódio na sanitização do cheiro-verde minimamente processado. Ciênc Tecnol Aliment. 2007;27(4):744-750.

[16] Brasil. Ministério da Saúde. Vigilância Epidemiológica das Doenças Transmitidas por Alimentos - VE-DTA [internet]. 2014 [acesso em 21 jan 2015]. Disponível em: http://www.anrbrasil.org.br/new/pdfs/2014

[17] Silva N, Junqueira VCA, Silveira NFA, Taniwaki MH, Santos RFS, Gomes RAR. Manual de Métodos de Análise Microbiológica de Alimentos e Água. 4a ed. São Paulo: Varela; 2010.

[18] Brasil. Ministério da Saúde. Agência Nacional de Vigilância Sanitária. Resolução RDC no 12, de 02 de janeiro de 2001. Regulamento técnico sobre padrões microbiológicos para alimentos. Diário Oficial da União. 10 jan 2001.

[19] Assis LLR, Uchida NS. Análise da qualidade microbiológica de hortaliças minimamente processadas comercializadas em campo mourão, PR. Braz J Surg Clin Res. 2013/2014;5(3):17-22.

[20] Inglaterra. Health Protection Agency. Guidelines for the microbiological quality of some ready-to-eat foods sampled at point of sale. Commun Dis Public Health. 2000;3(3):163p. 
[21] Arruda MC, Jacomino AP, Spoto MHF, Gallo CR, Moretti CL. Conservação de melão rendilhado minimamente processado sob atmosfera modificada ativa. Ciênc Tecnol Aliment. 2004;24(1):053-058.

[22] Campos J, Mourão J, Pestana N, Peixe L, Novais C, Antunes P. Microbiological quality of ready-to-eat salads: and underestimated vehicle of bacteria and clinically relevant antibiotic resistance genes. Int J Food Microbiol. 2013;166:464-470.

[23] Bennik MHJ, Vorstman W, Smid EJ, Gorris LGM. The influence of oxygen and carbon dioxide on the growth of prevalent Enterobacteriaceae and Pseudomonas species isolated from fresh and controlled-atmosphere-stored vegetabels. Food Microbiol.1998;15:459-469.

[24] Vankerschaver K, Willocx F, Smout C, Hendrickx M, Tobback P. The influence of temperature and gas mixtures on the growth of the intrinsic microrganisms on cut endive: predictive versus actual growth. Food Microbiol. 1996;13:427-440.

[25] Seow J, Ágoston R, Phua L, Yuk H. Microbiological quality of fresh vegetables and fruits sold in Singapore. Food Control. 2012;25:39-44.
[26] Silva N, Silveira NFA, Yokoya F, Okazaki MM. Ocorrência de Eschericbia coli O157:H7 em vegetais e resistência aos agentes de desinfecção de verduras. Ciênc Tecnol Aliment. 2003;23(2):167-173.

[27] Espanha. Real Decreto no 3484/2000 de 29 de diciembre, por el que se estabelecen las normas de higiene para la elaboración, distribuición y comercio de comidas preparadas. Boletín Oficial del Estado, Ministerio de la Presidencia, Gobierno de España. 12 jan 2001; 11: 14351441.

[28] Food and Agriculture Organization of United Nations FAO, World Health Organization - WHO. Microbiological hazards in fresh fruits and vegetables: meeting report. Microbiological risk assessment series. Roma; 2008.

[29] Cavalcante DA, Leite Junior BRC, Tribst AAL, Cristianini M. Sanitização de alface americana com água ozonizada para inativação de Escherichia coli O157:H7. Segurança Alimentar e Nutricional. 2014;21(1):373-378.

[30] Sant'ana AS, Franco BDGM, Schaffner DW. Risk of infection with Salmonella and Listeria monocytogenes due to consumption of ready-to-eat leafy vegetables in Brazil. Food Control. 2014;42:1-8. 